\title{
RESEARCH
}

\section{Curcumin exerts a protective effect against premature ovarian failure in mice}

\author{
Zhengjie Yan1,2, Youjin Dai3, Heling Fu³, Yuan Zheng3, Dan Bao3, Yuan Yin³, Qin Chen³, Xiaowei Nie4, \\ Qingting $\mathrm{HaO}^{3}$, Daorong $\mathrm{Hou}^{3}$ and Yugui Cui²
}

'College of Animal Science and Technology, Yangzhou University, Yangzhou, People's Republic of China

2State Key Laboratory of Reproductive Medicine, Center of Clinical Reproductive Medicine, The First Affiliated Hospital of Nanjing Medical University, Nanjing, People's Republic of China

${ }^{3}$ Key Laboratory of the Model Animal Research, Animal Core Facility of Nanjing Medical University, Nanjing Medical University, Nanjing, People's Republic of China

4Department of Reproductive Medicine, Affiliated Hospital of Nanjing University of Traditional Chinese Medicine, Nanjing, China

Correspondence should be addressed to D Hou or Y Cui: houdaorong@njmu.edu.cn or cuiygnj@njmu.edu.cn

\begin{abstract}
This study was designed to investigate the protective effect of curcumin against D-galactose (D-gal)-induced premature ovarian failure (POF) in mice. A mouse POF model was induced by subcutaneous injection of D-gal $(200 \mathrm{mg} / \mathrm{kg} /$ day) daily for 42 days. Mice in the curcumin group received both $D$-gal treatment and intraperitoneal injection of curcumin $(100 \mathrm{mg} / \mathrm{kg} /$ day $)$ for 42 days. Ovarian function, oxidative stress and apoptosis were evaluated. The P, E2 and SOD levels were higher, and the FSH, LH and MDA levels were significantly lower in the curcumin group than those in the D-gal group. The proportion of primordial follicles was also significantly higher in the curcumin group than that in the D-gal group. In addition, curcumin treatment after D-gal administration resulted in significantly lower Sod2, Cat, 8-OhdG, 4-HNE, NTY and senescence-associated protein P16 expression levels, higher Amh expression levels and less apoptosis in granulosa cells than was observed in the D-gal group. Moreover, the p-Akt, Nrf2 and HO-1 protein expression levels were significantly higher and the apoptosis-related cleaved caspase-3 and -9 protein expression levels were markedly lower in the curcumin group than in the D-gal group. In conclusion, curcumin effectively inhibited D-gal-induced oxidative stress, apoptosis and ovarian injury via a mechanism involving the Nrf2/HO-1 and $\mathrm{PI}$ KK/Akt signaling pathways, suggesting that curcumin is a potential protective agent against POF.
\end{abstract}

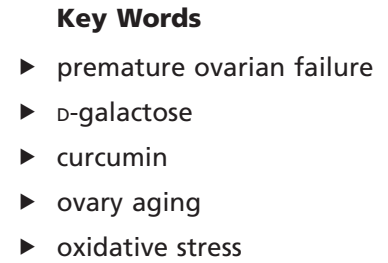

Journal of Molecular Endocrinology (2018) 60, 261-271

\section{Introduction}

Premature ovarian failure (POF), also called premature ovarian insufficiency (POI), affects approximately 1\% of women in the general population, in whom it causes amenorrhea and hypergonadotropic hypoestrogenism before the age of 40 years (Kaufman et al. 1988, Waggoner et al. 1990, Guerrero et al. 2000, Bandyopadhyay et al. 2003).
However, the pathological mechanism underlying POF remains unclear. The associated ovarian pathology is related to the toxic effects of galactose and its metabolites at both the ovarian and extraovarian levels (Campbell et al. 2010a,b, Rubio-Gozalbo et al. 2010). Moreover, there is no effective etiological treatment for POF. Hormone replacement 
therapy (HRT) is available to treat the symptoms of POF, and follicle donation is available for some POF patients seeking to become pregnant. However, HRT has been confirmed to confer a high risk of coronary heart disease, endometrial cancer and breast cancer in women with POF (Deady 2004).

POF is a common clinical feature of galactosemia (Waggoner et al. 1990, Guerrero et al. 2000), and women with galactosemia eventually develop POF (Kaufman et al. 1988). The estrous cycle of female mice is similar to but shorter than that of humans. The mouse D-galactose (D-gal)-induced POF model is used as a model of aging in mice and has been widely used to study the mechanisms underlying ovarian aging, because the accelerated aging observed in this model is very similar to observations in humans (Song et al. 1999, Semba et al. 2010). Aging is associated with increased deposition of advanced glycation end products (AGEs) and reactive oxygen species (ROS) in the myocardium, brain, liver, eye, red blood cells, kidney, bone, ovary, muscles and tendons (Kimura et al. 1996, Nerlich \& Schleicher 1999, Schinzel et al. 2001, Simm et al. 2004, Odetti et al. 2005, Haus et al. 2007, Kumar et al. 2007, Hyogo \& Yamagishi 2008). Many studies have indicated that AGEs and ROS exacerbate and accelerate the aging process and contribute to the early phases of age-related diseases, including atherosclerosis, cataracts, neurodegenerative diseases, renal failure, arthritis, ovarian senescence and age-related macular degeneration (Tian et al. 2005, Semba et al. 2010). D-gal administration can cause excessive ROS formation and AGE accumulation (Song et al. 1999, Mao et al. 2010, Lin et al. 2012). ROS-induced damage and AGE accumulation are widely accepted causes of aging that gradually damage ovarian functions (Semba et al. 2010). Therefore, D-gal has been used to induce the POF model (Bandyopadhyay et al. 2003). Curcumin (chemical name: 1, 7-bis (4-hydroxy-3-methoxyphenyl)-1, 6-heptadiene-3, 5-dione) (Aggarwal et al. 2005, Ak \& Gülçin 2008) is an active component of turmeric rhizomes (Curcuma longa Linn), which contain 3-5\% curcumin (Zhang et al. 2013). Curcumin has been scientifically demonstrated to function as an antioxidant (Fujisawa et al. 2004, Calabrese et al. 2008, Dinkova-Kostova \& Talalay 2008, Augustyniak et al. 2010), anti-inflammatory (Aggarwal \& Harikumar 2009, Wang et al. 2012, Ueki et al. 2013), anti-apoptotic (Geng et al. 2017) and antibacterial (Mun et al. 2013) substance. An increasing number of studies have shown that curcumin directly suppresses proliferation and promotes apoptosis in ovarian cancer cells (Shehzad et al. 2010, Watson et al. 2010, Terlikowska et al. 2014, Vallianou et al. 2015, Seo et al. 2016) and prevents the adverse effects of ovarian insufficiency (Tiwari-Pandey \& Ram Sairam 2009, Voznesens'ka et al. 2010, Alekseyeva et al. 2011, Aktas et al. 2012), ionizing radiation (Aktas et al. 2012), ischemia (Eser et al. 2015), oxidative stress (Qin et al. 2015) and mycotoxins (Qin et al. 2015) on ovarian function. Some studies have also demonstrated that curcumin and its analogues exert a stimulatory effect on ovarian functions, because they promote proliferation and reduce apoptosis in murine ovarian cells (Voznesens'ka et al. 2010, Aktas et al. 2012) while supporting murine ovarian folliculogenesis (Voznesens'ka et al. 2010, Alekseyeva et al . 2011) and steroidogenesis (Tiwari-Pandey \& Ram Sairam 2009). However, the effects of curcumin on experimentally D-gal-induced ovarian aging have not been reported. In this study, we investigate the protective effect of curcumin on ovarian aging in a D-gal-induced mouse model of POF.

\section{Materials and methods}

\section{Animals and treatment}

A total of $60 \mathrm{C} 57 \mathrm{BL} / 6$ female mice aged 7-8 weeks were used. The animals were obtained from the Animal Core Facility of Nanjing Medical University, Nanjing, China and housed under a 12-h darkness/light cycle in an animal facility with a controlled temperature $\left(20-25^{\circ} \mathrm{C}\right)$ and humidity (40\%-70\%). Food and water were provided ad libitum throughout the study. The mice were allowed to acclimatize for 1 week. Then, they were randomly divided into the three following groups with 20 mice per group: control group, D-gal group and curcumin group. The mice in the D-gal group were subcutaneously (s.c.) injected daily with D-gal ( $200 \mathrm{mg} / \mathrm{kg} /$ day) for 42 days (Park \& Choi 2012, He et al. 2017), the mice in the control group received an equal volume of saline (s.c. daily) for 42 days and the mice in the curcumin group received curcumin $(100 \mathrm{mg} / \mathrm{kg} / \mathrm{day})$ (Chainani-Wu 2003, Aktas et al. 2012) via intraperitoneal injection following a daily D-gal injection for 42 days. All experiments involving animals were approved by the Institutional Animal Care and Use Committee (IACUC) of Nanjing Medical University, and the methods were conducted in accordance with the approved guidelines. On the last day of drug administration (day 42), all mice were killed while under general anesthesia (induced using an intraperitoneal injection of pentobarbital sodium $(150 \mathrm{mg} / \mathrm{kg}))$. Blood was collected through a heart puncture, the left ovary was immediately excised and stored at $-80^{\circ} \mathrm{C}$ for biochemical analysis and the right ovary was fixed in $4 \%$ paraformaldehyde for histological studies.

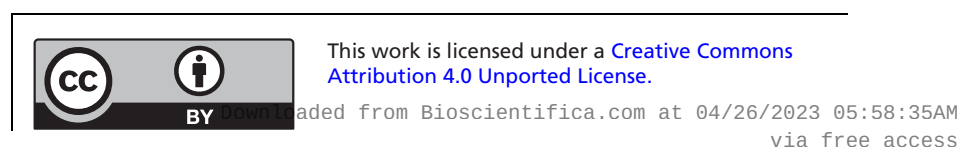




\section{Primordial follicle counting}

The right ovaries were fixed for $12 \mathrm{~h}$ in $4 \%$ paraformaldehyde and then embedded in paraffin. The tissues were serially sectioned (6- $\mu$ m thick), mounted on glass slides and stained with H\&E. The ovarian follicles were counted according to the methods described in a previous study (Tilly 2003, Bernal et al. 2010). Briefly, every fifth section was observed under a microscope. To avoid repeated counting of the same follicle, only follicles with a visible oocyte nucleus were included. The numbers of primordial follicles in all serial sections of an ovary were counted. The following follicle classification was used (Hirshfield \& Midgley 1978, Wang et al. 1991, Borgeest et al. 2002): type 1: primordial follicle, one layer of flattened granulosa cells surrounding the oocyte; type 2: primary follicle, one to two complete layers of cuboidal granulosa cells; type 3: secondary follicle, an oocyte surrounded by more than one layer of cuboidal granulosa cells with no visible antrum; type 4: antral follicle, an oocyte surrounded by multiple layers of cuboidal granulosa cells and containing one or more antral spaces, possibly with a cumulus oophorus and thecal layer and type 5: atretic follicle, a follicle that enters a degenerative process without ovulation. The oocyte nuclei in the atretic follicles shrink, the chromosomes and cytoplasm dissolve, the granulosa layer decreases and the follicular membrane cells are hypertrophic (Paulose et al. 2012). The primordial follicle ratio refers to the percentage of the primordial follicle number out of the total follicles. The atretic follicles were included in the denominator when calculating the proportion of primordial follicles or total follicles.

\section{Sample preparation and biochemical assays}

All blood samples were collected while the mice were in diestrus and allowed to clot at room temperature. Then, the samples were centrifuged at $900 \boldsymbol{g}$ for $10 \mathrm{~min}$ to harvest serum. Serum biochemical parameters, including the serum follicle-stimulating hormone (FSH), luteinizing hormone (LH), progesterone (P) and estradiol (E2) levels, were measured spectrophotometrically (Eon, BioTeK, Vermont, UT, USA) using the following commercially available ELISA kits: FSH (KA2330), LH (KA2332) (Novus Biologicals, Littleton,USA), E2 (582251) and P (582601) (Cayman Chemicals, Ann Arbor, MI, USA). The ovaries were washed in ice-cold saline and homogenized in $0.1 \mathrm{M}$ Tris- $\mathrm{HCl}$ buffer ( $\mathrm{pH}$ 7.4). The homogenates were centrifuged at $10,000 \boldsymbol{g}$ for $15 \mathrm{~min}$, and the supernatants were centrifuged at $100,000 \boldsymbol{g}$ for $1 \mathrm{~h}$. The resulting supernatant (cytosolic fraction) was used to determine the enzymatic activity and lipid peroxidation levels. The biochemical parameters of the ovaries, including the total superoxide dismutase (SOD) activity and malondialdehyde (MDA) level, were measured spectrophotometrically using commercially available kits for SOD (A001-1) and MDA (A003-1) (Jiancheng Bioengineering Institute, Nanjing, China).

\section{Q-PCR}

Total mRNA was extracted from the ovarian samples using the TRIzol reagent (B5704-1, Takara) according to the manufacturer's instructions and then treated with DNase I (2212, Takara) according to the manufacturer's protocol. The quality and quantity of the RNA were determined using a spectrophotometer (NanoDrop 2000c, Thermo Scientific). cDNA was immediately synthesized using the PrimeScript RT Reagent Kit (RR037A, Takara) according to the manual supplied by the manufacturer. Q-PCR was performed using a Light Cycler PCR QC Kit (Roche) and a 7300 Real-Time PCR System (LC96, Roche). The PCR primers are listed in Supplementary Table 1 (see section on supplementary data given at the end of this article). The housekeeping gene GAPDH was used as the internal reference. Expression of the target gene was normalized to GAPDH and calculated using the comparative quantification method $\left(2^{-\Delta \Delta \mathrm{Ct})}\right.$. Expression of the target genes was corrected to GAPDH prior to normalization. Firstly, the Ct value of each group was subtracted from the $\mathrm{Ct}$ value of the internal reference gene, which was named $\Delta \mathrm{Ct}$, as follows: $\Delta \mathrm{Ct}=\mathrm{Ct}$ (target gene) $-\mathrm{Ct}$ (internal reference gene). Secondly, the $\Delta \mathrm{Ct}$ of the experimental group was subtracted from the control group, and then the inverse of all of the results was taken to obtain $-\Delta \Delta \mathrm{Ct}$. Finally, the power operation of $-\Delta \Delta \mathrm{Ct}$ was performed in 2. The GraphPad Prism 5 software was used for chart production.

\section{Immunohistochemical staining}

For the immunohistochemical analysis, paraffinembedded sections were dewaxed and then subjected to heat-mediated antigen retrieval, which was performed by microwaving the sections for $20 \mathrm{~min}$ in $10 \mathrm{mM}$ sodium citrate ( $\mathrm{pH}$ 6.0). The sections were allowed to cool for $15 \mathrm{~min}$, briefly washed in deionized water and then rinsed twice in PBS. The sections were incubated for $30 \mathrm{~min}$ in $5 \%$ goat serum in DPBS containing $0.1 \%$

This work is licensed under a Creative Common Attribution 4.0 Unported License. 
Tween and $0.5 \%$ BSA. The sections were incubated overnight at $4^{\circ} \mathrm{C}$ with primary antibodies against 8-hydroxyguanosine (ab26842), 4-hydroxynonenal (ab48506), anti-CDKN2A/p16 (ab189034) (Abcam Biotechnology) and nitrotyrosine (sc-71007) (Millipore Biotechnology) at the appropriate dilutions. The secondary antibody in the Dako REAL EnVisio Detection System (K5007) (DAKO) was used to detect labeling. Then, the specimens were counterstained with hematoxylin for $1 \mathrm{~min}$. All sections were incubated under the same conditions and at the same time using the same antibody concentrations. The tissue sections were observed and photographed with a microscope and semi-quantified using the Image Pro Plus 6.0 software. The integrated optical density (IOD) was collected for each photograph. Five fields for each slice (five slides per animal) were randomly selected for blinded measurements ( $n=8$ per group). The images were quantified by the immunoreactive area (IA) in $\mu \mathrm{m}^{2}$ and the IOD. The staining intensity (SI) for each image was calculated as SI =IOD/IA, and the mean with standard deviation was obtained for each series.

\section{In situ TUNEL fluorescence staining assay}

The terminal deoxynucleotidyl transferase (TdT)mediated deoxyuridine triphosphate (dUTP) nick endlabeling (TUNEL) assay was performed according to the manufacturer's instructions (11684817910, Roche). Ovarian tissues were fixed in $4 \%$ paraformaldehyde overnight, dehydrated, embedded in paraffin, cut into $4-\mu \mathrm{m}$-thick sections and placed on numbered polylysine-coated glass slides. Deparaffinized tissue sections were incubated with proteinase $\mathrm{K}(20 \mathrm{mg} / \mathrm{mL})$ in a humidified chamber for $15 \mathrm{~min}$, and endogenous peroxidase activity was blocked by treating the sections with $3 \% \mathrm{H}_{2} \mathrm{O}_{2}$ for $10 \mathrm{~min}$. The sections were incubated with TdT labeling buffer at $37^{\circ} \mathrm{C}$ for $1 \mathrm{~h}$ in a moist chamber. Then, the sections were counterstained with DAPI. The TUNEL-positive cells stained green, and the nuclei were stained with DAPI (blue). To eliminate the histological differences between ovarian tissues, five random fields per slide (five slides per animal, eight animals per group, $n=8$ ) were examined. In total, 200 random fields $(5 \times 5 \times 8=200)$ per group were checked. The TUNEL-positive granulosa cells and the total granulosa cells in the antral follicles were counted. The rate of TUNEL-positive granulosa cells (\%) in the antral follicles was analyzed using the Image Pro Plus 6.0 software.

\section{Western blotting}

The Western blotting analysis was performed according to the methods described by Banerjee et al. (2012). Briefly, $50 \mu \mathrm{g}$ of total lysate obtained from ovarian tissue was subjected to $15 \%$ polyacrylamide gel electrophoresis and then transferred to a cellulose acetate membrane. The membranes were blocked with $1 \times$ casein solution for approximately $4 \mathrm{~h}$ and then incubated with rabbit monoclonal anti-Akt (4685), anti-p-Akt (Ser473) (4058), anti-cleaved caspase-3 (Asp175) (9664) or anti-cleaved caspase-9 (Asp330) (7237) antibodies obtained from Cell Signaling Technology, rabbit polyclonal anti-Nrf2 (sc-722) or anti-GAPDH (H-12) (sc-166574) antibodies or a mouse monoclonal anti-HO-1 (sc-390991) antibody obtained from Santa Cruz Biotechnology in blocking buffer for $2 \mathrm{~h}$ at room temperature. The membranes were washed 3 times with TBST and then incubated with a goat anti-rabbit IgG HRP-conjugated secondary antibody (sc-2004, Santa Cruz Biotechnology) or a goat anti-mouse IgG HRP-conjugated secondary antibody (sc-2005, Santa Cruz Biotechnology). Then, the membranes were washed 3 times in TBST, and the blots were imaged using the ChemiDoc XRS+ Molecular Imager (Bio-Rad) with the Pierce ECL Western Blotting Substrate (32209, Thermo Scientific) and analyzed using image analysis software (ImageJ 1.42). The housekeeping protein GAPDH was used as the internal reference. The Western blotting quantification was corrected to GAPDH expression prior to normalization.

\section{Statistical analysis}

All statistical analyses were performed using SPSS v.16. All results are shown as the mean \pm standard deviation (M \pm s.D.). All statistical comparisons were performed using one-way ANOVA followed by Duncan's multiple range post hoc analysis. A $P$ value $<0.05$ was considered significant.

\section{Results}

\section{Protective effects of curcumin on the HPG axis and ovarian Amh mRNA expression}

The D-gal treatment group had significantly increased serum FSH and LH levels $(P<0.05$ and $P<0.01)$ and significantly decreased $\mathrm{E} 2$ and $P$ levels $(P<0.01)$ compared to those in the control (Fig. 1A, B, C and D). Due to insufficient sensitivity and stability, an enzyme immunoassay (ELISA) was not used to test the serum anti-Müllerian hormone $(\mathrm{AMH})$ level. Instead, Amh mRNA expression in the ovarian tissue was tested using q-PCR. Interestingly, Amh

This work is licensed under a Creative Common Attribution 4.0 Unported License. 


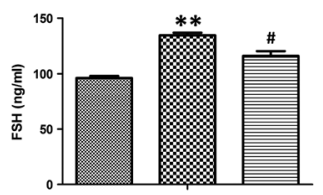

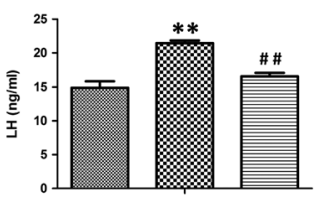

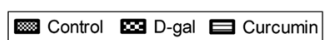

C

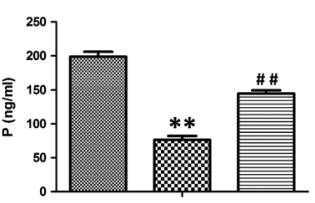

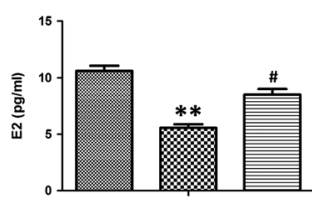

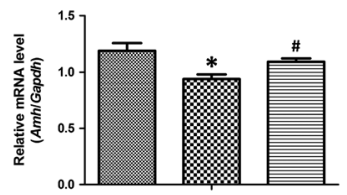

Figure 1

Protective effects of curcumin on the HPG axis and ovarian AMH. The serum FSH (A), LH (B), E2 (C) and P (D) levels were tested in three groups, and AMH mRNA expression in the ovarian tissues (E) was also tested. Ten mice per group were examined. All data are shown as the mean \pm S.D. Statistical significance: $* P<0.05$ and $* * P<0.01$ vs the control group, $\# P<0.05$ and $\# \#<0.01$ vs the $D$-gal group.

mRNA expression was significantly decreased in the D-gal treatment group compared with that in the control group (Fig. 1E). In the POF model induced by D-gal, curcumin treatment significantly decreased the serum FSH and $\mathrm{LH}$ levels $(P<0.05$, Fig. $1 \mathrm{~A}$ and $\mathrm{B})$ and increased the serum E2 and $P$ levels $(P<0.01$, Fig. $1 C$ and $D)$ and the ovarian $A m h$ expression level $(P<0.05$, Fig. $1 \mathrm{E})$.

\section{Protective effect of curcumin on follicular development in the POF model}

Follicle counting was performed after H\&E staining (Fig. 2A, B, C, D, E and F). The follicle classification was based on the characteristics proposed by Hirshfield \& Midgley (1978). Counting of the primordial follicles showed that D-gal treatment reduced the proportion of primordial follicles compared to that in the control group $(P<0.01$, Fig. $2 \mathrm{G}$ and $\mathrm{H})$. Significantly more follicles were counted at the different developmental stages of maturation in the curcumin treatment group than in the D-gal model group $(P<0.05$ or $P<0.01$, Fig. $2 \mathrm{H})$.

\section{Effects of D-gal and curcumin on oxidative stress}

The total SOD enzyme activity was significantly lower in the ovarian tissues from the D-gal treatment group than in the tissues from the control group $(P<0.01$, Fig. 3A), and the MDA level was significantly higher in the treated group than in the control group $(P<0.01$, Fig. 3B). Curcumin treatment resulted in markedly higher SOD levels and lower MDA levels than the levels in the D-gal group (all $P<0.01$, Fig. 3A and B). Cat and Sod2 mRNA expression was tested using Q-PCR (Fig. 3C and D). Corresponding with the changes in the SOD activity and MDA level, Cat expression was significantly increased in the D-gal group compared to that in the control group $(P<0.01)$, and curcumin treatment partially but significantly rescued the effect of D-gal $(P<0.05$, Fig. 3C). However, the change in Sod2 expression was seemingly abnormal. The Sod 2 mRNA expression level was significantly increased in the D-gal model $(P<0.01$, Fig. 3D), whereas curcumin treatment partially and significantly rescued the effect of D-gal $(P<0.01)$.
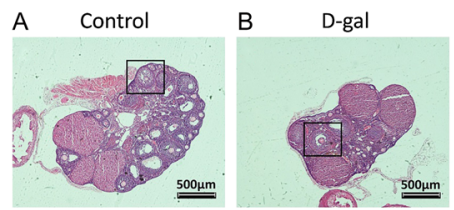

C Curcumin

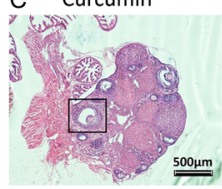

D
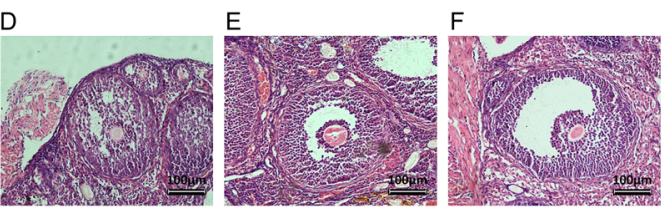

G

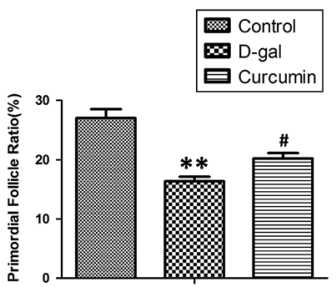

$\mathrm{H}$

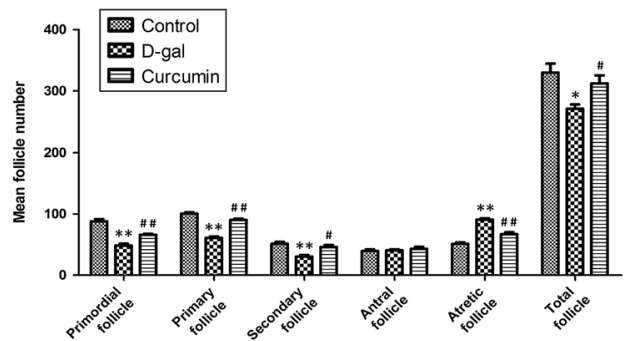

Figure 2

Effect of curcumin on follicular development in the POF model. Follicles were observed after H\&E staining (A, B, C, D, E and F). The follicle classification was based on the characteristics proposed by Hirshfield and Midgley. (G) Primordial follicle ratio counting was performed in the three groups. Ten mice per group were examined. The primordial follicle ratio refers to the percentage of the primordial follicle number to the total follicle number. (H) The numbers of those follicles at different developmental stages of maturation were summarized. ${ }^{*} P<0.05$ and $* * P<0.01$ vs the control group, $\# P<0.05$ and $\# P<0.01$ vs the $\mathrm{D}$-gal group.

http://jme.endocrinology-journals.org https://doi.org/10.1530/JME-17-0214 (c) 2018 The authors Published by Bioscientifica Ltd. Printed in Great Britain

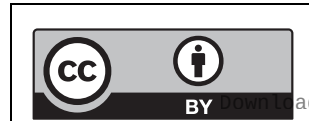

This work is licensed under a Creative Commons Attribution 4.0 Unported License. 

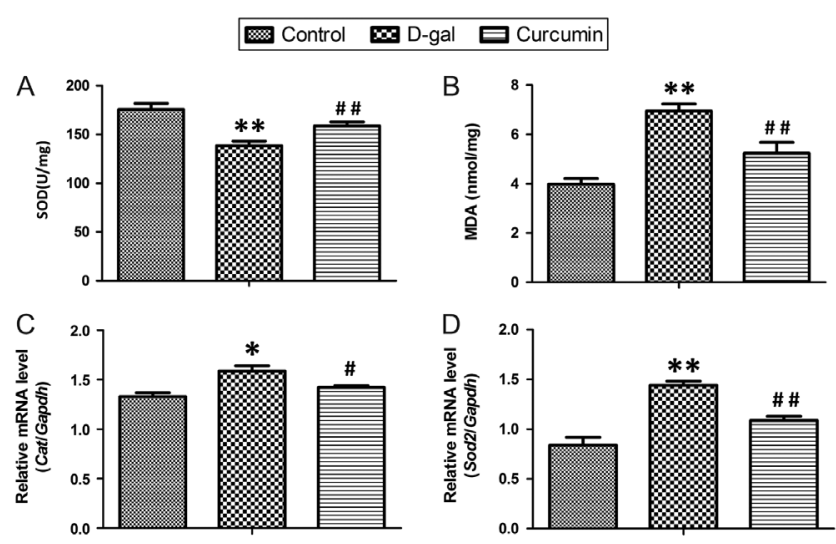

Figure 3

Effects of D-gal and curcumin on oxidative stress. The total SOD enzyme activity (A) and the MDA level (B) were measured in the ovarian tissues. Cat (C) and Sod2 (D) mRNA expression was tested using Q-PCR. Ten mice per group were examined. All data are shown as the mean \pm s.D. Statistical significance: ${ }^{*} P<0.05$ and $* * P<0.01$ vs the control group, ${ }^{*} P<0.05$ and $\# P<0.01$ vs the $D$-gal group.

\section{Protective effect of curcumin on D-gal-induced ovarian cell apoptosis}

In the TUNEL assay, the nuclei of the TUNEL-positive (apoptotic) cells stained green (Fig. 4A). The number of apoptotic granulosa cells in the antral follicles was assessed in the three groups. More TUNEL-positive cells were detected in the D-gal group than in the control group $(P<0.01$, Fig. 4B). Curcumin significantly decreased the number of TUNEL-positive cells compared with the number in the D-gal model group, suggesting a protective effect on D-gal-induced ovarian cell apoptosis $(P<0.01)$.

\section{Effects of curcumin on 4-HNE, NTY, 8-OHdG and p16 protein expression}

The cellular locations of the 4-HNE, NTY, 8-OHdG and p16 proteins were examined using immunohistochemistry (Fig. 5). The 4-HNE, NTY and 8-OHdG proteins were mainly located in the ovarian interstitial cells. The 4-HNE, 8-OhdG and NTY protein expression levels were significantly higher in the D-gal group than in the control group $(P<0.01$, Fig. 5B), whereas the expression levels were partially and significantly decreased in the curcumin treatment group $(P<0.01$ and $P<0.05$, respectively).

Interestingly, the senescence-associated $\mathrm{p} 16$ protein was mainly located in follicular granulosa cells and oocytes (Fig. 5A), and relatively lower p16 expression was observed in the ovarian interstitial cells. Corresponding to the 4-HNE, 8-OhdG and NTY protein expression levels, D-gal treatment induced a significant increase in p16
A
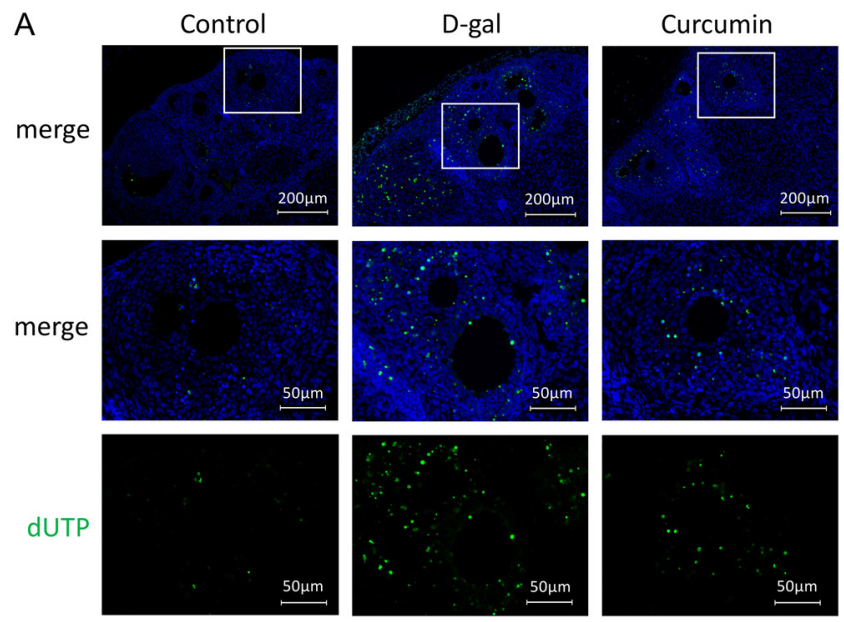

DAPI
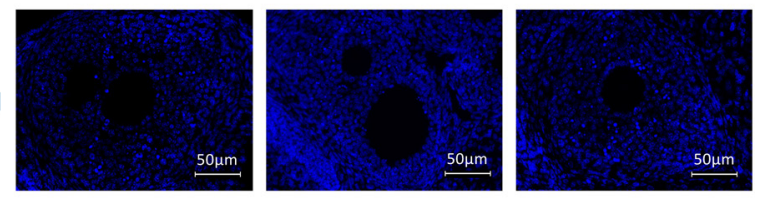

B

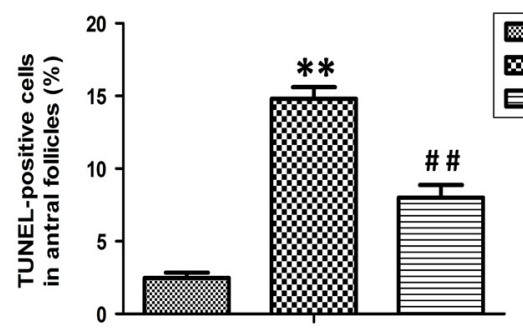

Figure 4

Effect of curcumin on D-gal-induced apoptosis of ovarian cells. Apoptosis was analyzed using in situ TUNEL fluorescence staining (A). In the TUNEL assay, the nuclei of TUNEL-positive (apoptotic) cells stained green. Five random fields per section (five sections per tissue from a mouse) were examined in each experiment. The TUNEL-positive granulosa cells and total granulosa cells in the antral follicles were counted. The number of TUNEL-positive granulosa cells (\%) was compared among the three groups $(n=8)$ (B). Statistical significance: $* P<0.01$ and $* * P<0.01$ vs the control group; ${ }^{P} P<0.01$ and ${ }^{\#} P<0.01$ vs the $D$-gal group.

protein expression, whereas curcumin treatment rescued the effect of D-gal treatment $(P<0.01$, Fig. 5B).

\section{Effect of curcumin on related pathways in the ovary}

We investigated the potential mechanisms involved in the effects of curcumin on D-gal-induced ovarian aging. The expression levels of apoptosis- and oxidative stress signal pathway-associated markers were assessed by Western blotting (Fig. 6). Total Akt protein expression was the same in each group, whereas the p-Akt level was markedly lower in the D-gal group than in the control group $(P<0.01)$ and was significantly higher in the curcumin group than in the D-gal group $(P<0.01)$. The cleaved caspase-3 and cleaved 
A

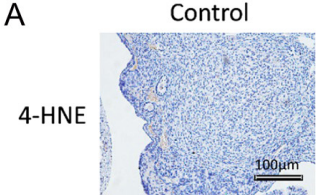

$100 \mathrm{~mm}$
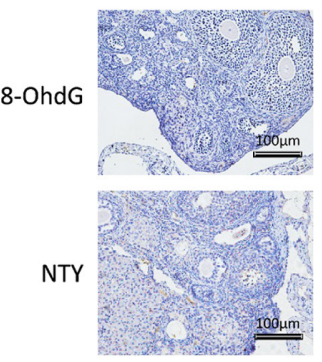

P16

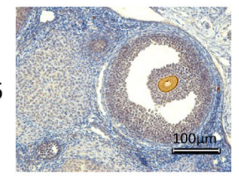

D-gal

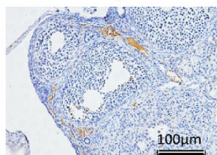

$\underline{100 \mu \mathrm{m}}$
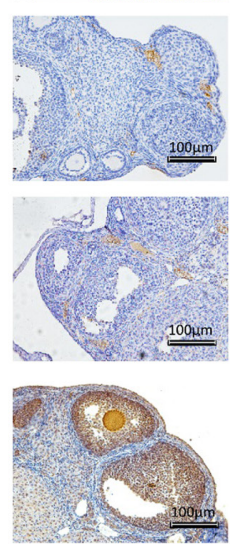

Curcumin

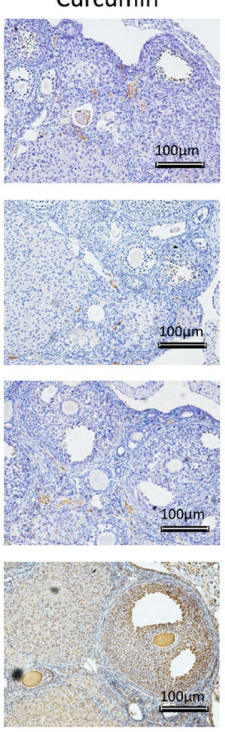

B

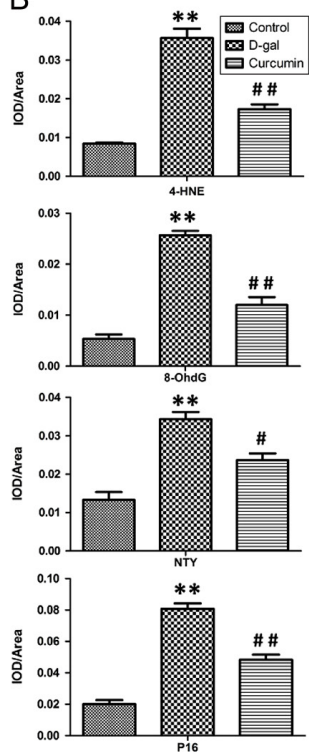

Figure 5

Effects of curcumin on 4-HNE, NTY, 8-OHdG and p16 protein expression. The cellular locations of these proteins were observed using immunohistochemistry (A), and 4-HNE, NTY, 8-OHdG and p16 expression was quantitatively analyzed $(n=8)$ (B). Data are shown as the mean \pm s.D. Statistical significance: $* P<0.01$ and $* * P<0.01$ vs the control group; ${ }^{\# P}<0.05$ and $\# P<0.01$ vs the $D-g a l$ group. caspase-9 levels were significantly lower in the curcumin group than in the D-gal group $(P<0.01)$; moreover, the Nrf2 and HO-1 protein expression levels were significantly lower in the D-gal group than in the control group $(P<0.01)$, whereas the Nrf2 and HO-1 expression levels were significantly higher in the curcumin group than in the D-gal group $(P<0.05$ and $P<0.01$, respectively).

\section{Discussion}

In the present study, a mouse POF model was successfully induced by D-galactose. D-galactose treatment resulted in increased ROS and AGEs, increased granulosa cell apoptosis and damaged follicular development. Curcumin partially rescued the effects of D-gal in the mouse POF model via a mechanism involving the Nrf2/HO-1 and PI3K/Akt signaling pathways.

Many studies have shown that D-gal directly induces oxidative stress in vivo and that galactose toxicity attenuates FSH bioactivity and inhibits E2 production from granulose cells (Banerjee et al. 2012). We found that the serum FSH and LH levels were significantly increased and the E2 and P levels were decreased in mice treated with $\mathrm{D}$-gal. The number of atretic follicles was increased by the D-gal treatment; conversely, the decreased number of primordial, primary and secondary follicles resulted in a decreased number of total follicles, which was in line with a previous report (Bandyopadhyay et al. 2003). AMH is a very important early marker of ovarian aging (Visser et al. 2006, Soto et al. 2009, Tolikas et al. 2011) and reflects the size of the ovarian follicle pool (Feyereisen et al. 2006). Lower Amh expression

$$
\text { http://jme.endocrinology-journals.org }
$$
https://doi.org/10.1530/JME-17-0214
C 2018 The authors Published by Bioscientifica Ltd. Printed in Great Britain has been detected long before normal menopause (Sanders et al. 2009, Seifer et al. 2011) and during the normal course of aging in mice (Kevenaar et al. 2006). We also found that ovarian Amh expression was significantly decreased by D-gal. Thus, the use of D-gal successfully induced the mouse POF model in the present study.

Curcumin is an antioxidant (Augustyniak et al. 2010), anti-inflammatory (Ueki et al. 2013), anti-apoptotic (Geng et al. 2017) and antibacterial (Mun et al. 2013) substance. Curcumin was demonstrated to exert a stimulatory effect on ovarian function, because curcumin promoted folliculogenesis and reduced apoptosis in murine ovarian cells (Voznesens'ka et al. 2010, Aktas et al. 2012). This study was designed to investigate the protective effects of curcumin on ovarian aging in a D-gal-induced mouse model of POF. We found that curcumin decreased the FSH and LH levels and increased the E2 and $P$ levels in the mouse POF model. Interestingly, ovarian AMH expression was significantly increased by curcumin, whereas the total number of follicles increased with the increased numbers of primordial, primary and secondary follicles. Curcumin partially and significantly rescued the effects of D-gal in the POF model, suggesting that curcumin might regulate the reproductive endocrine function and promote follicular development or the maintenance of primordial follicles.

We found that the total SOD enzyme activity was decreased and the MDA level was increased in the D-galactose-induced POF model, whereas Cat and Sod2 expression was significantly increased. Superoxide dismutase (SOD) is a type of enzyme that alternatively catalyzes dismutation of the superoxide $\left(\mathrm{O}^{2-}\right)$ radical 
A
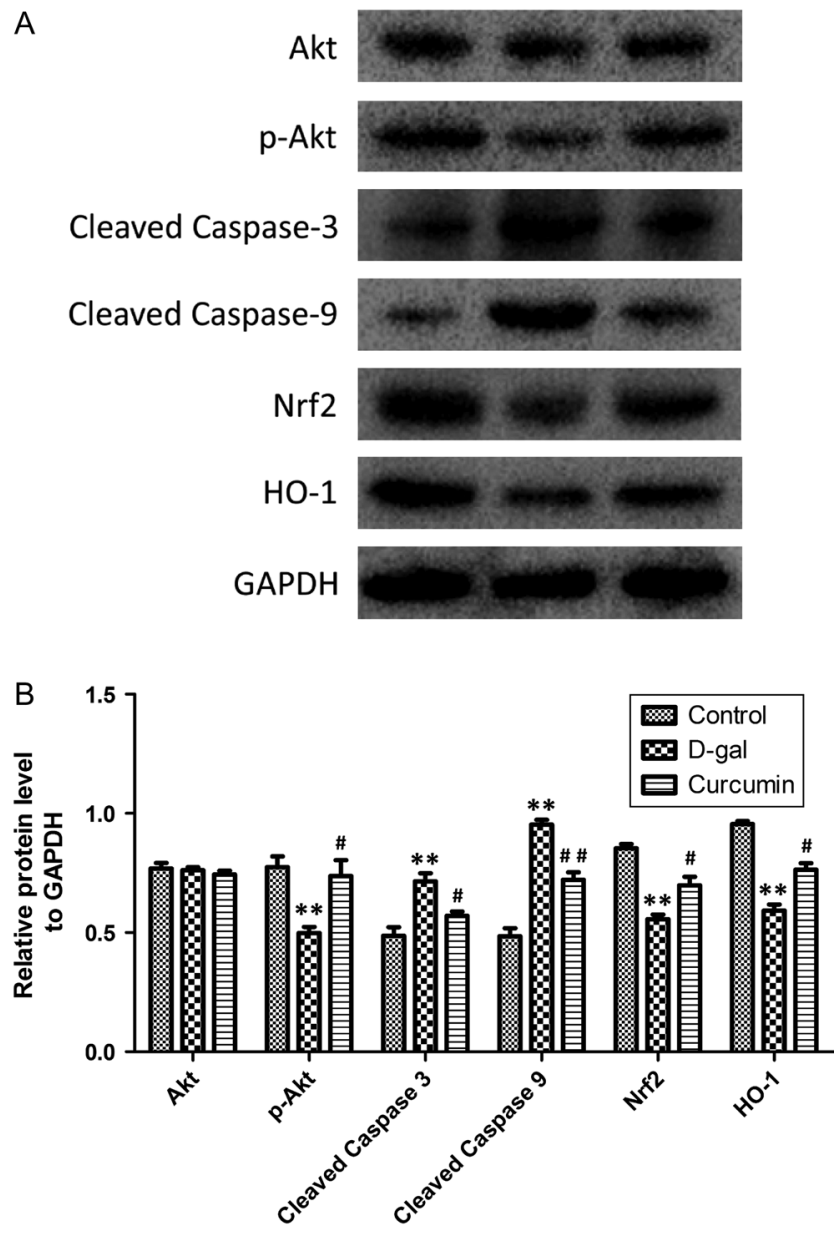

Figure 6

Effect of curcumin on the expression of apoptosis- and oxidative stress-associated factors in ovarian tissues. The Akt, p-Akt, cleaved caspase-3, cleaved caspase-9, Nrf2 and HO-1 protein expression levels in ovarian tissues were observed using Western blotting (A). The Akt, p-Akt, $\mathrm{Nrf2}$ and HO-1 protein expression levels were quantitatively analyzed $(n=8)$ (B). Data are shown as the mean \pm s.D. Statistical significance: ${ }^{*} P<0.01$ and ${ }^{*} P<0.01$ vs the control group; ${ }^{*} P<0.05$ and $\# P<0.01$ vs the D-gal group.

into either ordinary molecular oxygen $\left(\mathrm{O}_{2}\right)$ or hydrogen peroxide $\left(\mathrm{H}_{2} \mathrm{O}_{2}\right)$. The increased ROS production induced by D-gal is related to the inhibition of SOD activity. Three forms of superoxide dismutase (SOD1, SOD2 and SOD3) are expressed in all mammals. SOD2, which is the mitochondrial SOD and is also known as manganesedependent superoxide dismutase (MnSOD), is a member of the iron/manganese superoxide dismutase family (Scandalios 2005). SOD2 and catalase are the two most important antioxidant enzymes in the body, and their expression levels are increased following oxidative stress (Scandalios 2005, Zhang et al. 2014). D-galactose, which is a reducing sugar that reacts readily with the free amines of amino acids in proteins and peptides to form AGEs
(Bucala \& Cerami 1992, Vlassara et al. 1994), produces acetaldehyde and hydrogen peroxide under the action of galactose oxidase and thus increases ROS, resulting in the aging of cells (Ho et al. 2003). Several studies have shown that oxidative stress can reduce the number of follicles and oocytes (Tarín 1995, 1996). Miyamoto et al. (2010) reported that oxidative stress caused a significant decrease in the number of follicles and the ovulated oocytes during repeated ovulation. We found that curcumin increased the total SOD activity and decreased MDA. Curcumin exerts a protective effect by inhibiting oxidative stress in a D-gal-induced model of ovarian aging, and its effects may be mediated via the suppression of ROS and superoxide anion free radicals (Suckow \& Suckow 2006, Sikora et al. 2010).

The results showed that 4-HNE, NTY and 8-OHdG expression was mainly located in ovarian interstitial cells, and curcumin decreased the expression of those proteins. The D-gal-induced effects on ROS, AGEs and other factors on cellular aging should be extensive (Song et al. 1999). Factors such as 8-OhdG, 4-HNE and NTY, which are mainly located in somatic cells, are involved in the aging process related to ROS and AGEs. Interestingly, the p16 protein was highly expressed in ovarian follicles, including oocytes, granular cells and cumulus cells, and expressed at low levels in interstitial cells. The p16 protein negatively regulates cell proliferation and division and promotes apoptosis and senescence; thus, it affects the cell cycle and G1-S conversion by competitively suppressing the combination between CDK4/6 and cyclin D within G1 phase. We found that p16 expression in follicles was significantly increased in the D-gal-induced model and that curcumin significantly decreased D-gal-induced p16 expression. The p16 expression level was positively related to the follicular number and negatively related to the $\mathrm{E}_{2}$ and P levels. p16 expression was low in young animal tissues and subsequently increased with age (Kim et al. 2002, Attema et al. 2009). Excessive p16 expression can induce premature aging in cells (Attema et al. 2009). Baker and coworkers found that the aging cells reactivated and aging-associated phenotypes were reduced by silencing p16 protein expression (Baker et al. 2011). However, how p16 participates in ovarian aging through oxidative stress is unclear (Kim et al. 2002, Attema et al. 2009). We visualized an important effect of p16 on oxidative stress in ovarian follicles and found that curcumin also exerted a protective effect against ovarian aging partially through the downregulation of p16.

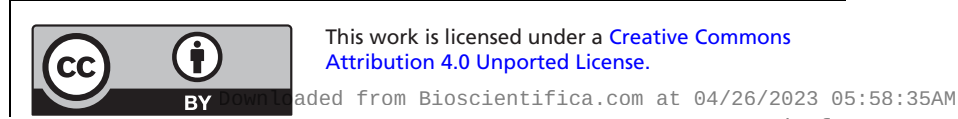


In the present study, we found that curcumin partially rescued the effects of D-gal via multiple mechanisms, including the inhibition of oxidative stress and granular cell apoptosis, as described in other reports (Suckow \& Suckow 2006, Sikora et al. 2010). Our results also showed that curcumin significantly increased p-Akt, HO-1 and Nrf2 expression in ovarian tissues and decreased the expression of the apoptosisrelated proteins cleaved caspase-3 and -9. PI3K/AKT signaling is widely accepted as a key pathway that regulates cell survival (Atif et al. 2015). Upregulation of phosphorylated PI3K and AKT can inhibit both the release of Bad and Bax and the activation of downstream pro-apoptotic proteins, such as caspases, resulting in the suppression of apoptosis (Rong \& Distelhorst 2008, Atif et al. 2015). Nrf2 can bind to antioxidant response elements (AREs) in the promoter regions of Nrf2 target genes, which remove ROS via sequential enzymatic reactions, such as HO-1 (Gozzelino et al. 2010). The induction of HO-1 is an adaptive response to oxidative stress (Paine et al. 2010). Curcumin has also been reported to activate Nrf2 to upregulate enzymes involved in antioxidant defenses, including SOD and HO-1 (Balogun et al. 2003, Zingg et al. 2013). Our results indicated that curcumin attenuated D-gal-induced oxidative stress injury in the ovary partly by activating the PI3K/Akt and Nrf2/HO-1 pathways.

In conclusion, curcumin effectively inhibited D-galinduced oxidative stress, apoptosis and ovarian injury via multiple mechanisms, including the Nrf2/HO-1 and PI3K/Akt signaling pathways. These results suggest that curcumin as an antioxidant is a potential protective agent against POF.

\section{Supplementary data}

This is linked to the online version of the paper at https://doi.org/10.1530/ JME-17-0214.

\section{Declaration of interest}

The authors declare that there is no conflict of interest that could be perceived as prejudicing the impartiality of the reported research.

\section{Funding}

This work was supported by the the National Key Research and Development Program of China (2017YFC1001602), Science and Technology Development Key Projects Fund of Nanjing Medical University (2016NJMUZD020), the Nature and Science Foundation of China (81270746), the Jiangsu Province Special Program of Medical Science (BL2012009 and ZX201110) and a project funded by PAPD of the Priority Academic Program Development of Jiangsu High Education Institutions (JX10231802).

\section{References}

Aggarwal BB \& Harikumar KB 2009 Potential therapeutic effects of curcumin, the anti-inflammatory agent, against neurodegenerative, cardiovascular, pulmonary, metabolic, autoimmune and neoplastic diseases. International Journal of Biochemistry and Cell Biology $\mathbf{4 1}$ 40-59. (https://doi.org/10.1016/j.biocel.2008.06.010)

Aggarwal BB, Aggarwal MS \& Shishodia S 2005 Curcumin derived from turmeric (Curcuma longa): a spice for all seasons.

Phytopharmaceuticals in Cancer Chemoprevention 23 349-387. (https:// doi.org/10.1201/9780203506707.ch23)

Ak T \& Gülçin I 2008 Antioxidant and radical scavenging properties of curcumin. Chemico-biological Interactions 174 27-37. (https://doi. org/10.1016/j.cbi.2008.05.003)

Aktas C, Kanter M \& Kocak Z 2012 Antiapoptotic and proliferative activity of curcumin on ovarian follicles in mice exposed to whole body ionizing radiation. Toxicology and Industrial Health 28 852-863. (https://doi.org/10.1177/0748233711425080)

Alekseyeva IN, Makogon NV, Bryzgina TM, Voznesenskaya TY \& Sukhina VS 2011 Effects of NF-кB blocker curcumin on oogenesis and immunocompetent organ cells in immune ovarian injury in mice. Bulletin of Experimental Biology and Medicine $151432-435$. (https://doi.org/10.1007/s10517-011-1349-1)

Atif F, Yousuf S \& Stein DG 2015 Anti-tumor effects of progesterone in human glioblastoma multiforme: role of PI3K/Akt/mTOR signaling. Journal of Steroid Biochemistry and Molecular Biology 146 62-73. (https://doi.org/10.1016/j.jsbmb.2014.04.007)

Attema JL, Pronk CJ, Norddahl GL, Nygren JM \& Bryder D 2009 Hematopoietic stem cell ageing is uncoupled from p16 INK4Amediated senescence. Oncogene 28 2238-2243. (https://doi. org/10.1038/onc.2009.94)

Augustyniak A, Bartosz G, Cipak A, Duburs G, Horáková L, Luczaj W, Majekova M, Odysseos AD, Rackova L, Skrzydlewska E, et al. 2010 Natural and synthetic antioxidants: an updated overview. Free Radical Research 44 1216-1262. (https://doi.org/10.3109/10715762.20 10.508495)

Baker DJ, Wijshake T, Tchkonia T, LeBrasseur NK, Childs BG, van de Sluis B, Kirkland JL \& van Deursen JM 2011 Clearance of p16Ink4apositive senescent cells delays ageing-associated disorders. Nature 479 232-236. (https://doi.org/10.1038/nature10600)

Balogun E, Hoque M, Gong P, Killeen E, Green CJ, Foresti R, Alam J \& Motterlini R 2003 Curcumin activates the haem oxygenase-1 gene via regulation of Nrf2 and the antioxidant-responsive element. Biochemical Journal 371 887-895. (https://doi.org/10.1042/ bj20021619)

Bandyopadhyay S, Chakrabarti J, Banerjee S, Pal AK, Goswami SK, Chakravarty BN \& Kabir SN 2003 Galactose toxicity in the rat as a model for premature ovarian failure: an experimental approach readdressed. Human Reproduction 18 2031-2038. (https://doi. org/10.1093/humrep/deg414)

Banerjee S, Chakraborty P, Saha P, Bandyopadhyay SA, Banerjee S \& Kabir SN 2012 Ovotoxic effects of galactose involve attenuation of follicle-stimulating hormone bioactivity and up-regulation of granulosa cell p53 expression. PLoS ONE 7 e30709. (https://doi. org/10.1371/journal.pone.0030709)

Bernal AB, Vickers MH, Hampton MB, Poynton RA \& Sloboda DM 2010 Maternal undernutrition significantly impacts ovarian follicle number and increases ovarian oxidative stress in adult rat offspring. PLOS ONE 5 e15558. (https://doi.org/10.1371/journal.pone.0015558)

Borgeest C, Symonds D, Mayer LP, Hoyer PB \& Flaws JA 2002 Methoxychlor may cause ovarian follicular atresia and proliferation of the ovarian epithelium in the mouse. Toxicological Sciences $\mathbf{6 8}$ 473-478. (https://doi.org/10.1093/toxsci/68.2.473)

Bucala R \& Cerami A 1992 Advanced glycosylation: chemistry, biology, and implications for diabetes and aging. Advances in Pharmacology 23 1-34. (https://doi.org/10.1016/S1054-3589(08)60961-8)

This work is licensed under a Creative Common Attribution 4.0 Unported License. 
Calabrese V, Bates TE, Mancuso C, Cornelius C, Ventimiglia B, Cambria MT, Di Renzo L, De Lorenzo A \& Dinkova-Kostova AT 2008 Curcumin and the cellular stress response in free radical-related diseases. Molecular Nutrition and Food Research 52 1062-1073. (https://doi.org/10.1002/mnfr.200700316)

Campbell BK, Kendall NR, Onions V \& Scaramuzzi RJ 2010a The effect of systemic and ovarian infusion of glucose, galactose and fructose on ovarian function in sheep. Reproduction 140 721-732. (https:// doi.org/10.1530/REP-10-0185)

Campbell BK, Onions V, Kendall NR, Guo L \& Scaramuzzi RJ 2010b The effect of monosaccharide sugars and pyruvate on the differentiation and metabolism of sheep granulosa cells in vitro. Reproduction $\mathbf{1 4 0}$ 541-550. (https://doi.org/10.1530/REP-10-0146)

Chainani-Wu N 2003 Safety and anti-inflammatory activity of curcumin: a component of tumeric (Curcuma longa). Journal of Alternative and Complementary Medicine 9 161-168. (https://doi. org/10.1089/107555303321223035)

Deady J 2004 Clinical monograph: hormone replacement therapy. Journal of Managed Care Pharmacy 10 33-47. (https://doi. org/10.18553/jmcp.2004.10.1.33)

Dinkova-Kostova AT \& Talalay P 2008 Direct and indirect antioxidant properties of inducers of cytoprotective proteins. Molecular Nutrition and Food Research 52 S128-S138. (https://doi.org/10.1002/mnfr.200700195)

Eser A, Hizli D, Haltas H, Namuslu M, Kosus A, Kosus N \& Kafali H 2015 Effects of curcumin on ovarian ischemia-reperfusion injury in a rat model. Biomedical Reports 3 807-813. (https://doi.org/10.3892/br.2015.515)

Feyereisen E, Méndez Lozano DH, Taieb J, Hesters L, Frydman R \& Fanchin R 2006 Anti-Müllerian hormone: clinical insights into a promising biomarker of ovarian follicular status. Reproductive Biomedicine Online 12 695-703. (https://doi.org/10.1016/S1472-6483(10)61081-4)

Fujisawa S, Atsumi T, Ishihara M \& Kadoma Y 2004 Cytotoxicity, ROSgeneration activity and radical-scavenging activity of curcumin and related compounds. Anticancer Research 24 563-569.

Geng X, Hong Q, Wang W, Zheng W, Li O, Cai G, Chen X \& Wu D 2017 Biological membrane-packed mesenchymal stem cells treat acute kidney disease by ameliorating mitochondrial-related apoptosis. Scientific Reports 7 41136. (https://doi.org/10.1038/srep41136)

Gozzelino R, Jeney V \& Soares MP 2010 Mechanisms of cell protection by heme oxygenase-1. Annual Review of Pharmacology and Toxicology 50 323-354. (https://doi.org/10.1146/annurev. pharmtox.010909.105600)

Guerrero NV, Singh RH, Manatunga A, Berry GT, Steiner RD \& Elsas LJ 2000 Risk factors for premature ovarian failure in females with galactosemia. Journal of Pediatrics 137 833-841. (https://doi. org/10.1067/mpd.2000.109148)

Haus JM, Carrithers JA, Trappe SW \& Trappe TA 2007 Collagen, crosslinking, and advanced glycation end products in aging human skeletal muscle. Journal of Applied Physiology 103 2068-2076. (https:// doi.org/10.1152/japplphysiol.00670.2007)

He L, Ling L, Wei T, Wang Y \& Xiong Z 2017 Ginsenoside Rg1 improves fertility and reduces ovarian pathological damages in premature ovarian failure model of mice. Experimental Biology and Medicine 242 683-691. (https://doi.org/10.1177/1535370217693323)

Hirshfield AN \& Midgley AR Jr 1978 Morphometric analysis of follicular development in the rat. Biology of Reproduction 19 597-605. (https:// doi.org/10.1095/biolreprod19.3.597)

Ho SC, Liu JH \& Wu RY 2003 Establishment of the mimetic aging effect in mice caused by D-galactose. Biogerontology 4 15-18. (https://doi. org/10.1023/A:1022417102206)

Hyogo H \& Yamagishi S 2008 Advance glycation end products (AGEs) and their involvement in liver disease. Current Pharmaceutical Design 14 969-972. (https://doi.org/10.2174/138161208784139701)

Kaufman FR, Xu YK, Ng WG \& Donnell GN 1988 Correlation of ovarian function with galactose-1-phosphate uridyl transferase levels in galactosemia. Journal of Pediatrics 112 754-756. (https://doi. org/10.1016/S0022-3476(88)80697-8)
Kevenaar ME, Meerasahib MF, Kramer P, van de Lang-Born BM, de Jong FH, Groome NP, Themmen AP \& Visser JA 2006 Serum anti-mullerian hormone levels reflect the size of the primordial follicle pool in mice. Endocrinology 147 3228-3234. (https://doi.org/10.1210/en.2005-1588)

Kim H, You S, Farris J, Kong BW, Christman SA, Foster LK \& Foster DN 2002 Expression profiles of p53-, p16(INK4a)-, and telomereregulating genes in replicative senescent primary human, mouse, and chicken fibroblast cells. Experimental Cell Research 272 199-208. (https://doi.org/10.1006/excr.2001.5420)

Kimura T, Takamatsu J, Ikeda K, Kondo A, Miyakawa T \& Horiuchi S 1996 Accumulation of advanced glycation end products of the Maillard reaction with age in human hippocampal neurons. Neuroscience Letters 208 53-56. (https://doi.org/10.1016/0304-3940(96)12537-4)

Kumar PA, Kumar MS \& Reddy GB 2007 Effect of glycation on alphacrystallin structure and chaperone-like function. Biochemical Journal 408 251-258. (https://doi.org/10.1042/BJ20070989)

Lin N, Zhang H \& Su Q 2012 Advanced glycation end-products induce injury to pancreatic beta cells through oxidative stress. Diabetes and Metabolism 38 250-257. (https://doi.org/10.1016/j.diabet.2012.01.003)

Mao GX, Deng HB, Yuan LG, Li DD, Li YY \& Wang Z 2010 Protective role of salidroside against aging in a mouse model induced by D-galactose. Biomedical and Environmental Sciences 23 161-166. (https://doi.org/10.1016/S0895-3988(10)60047-5)

Miyamoto K, Sato EF, Kasahara E, Jikumaru M, Hiramoto K, Tabata H, Katsuragi M, Odo S, Utsumi K, Inoue M, et al. 2010 Effect of oxidative stress during repeated ovulation on the structure and functions of the ovary, oocytes, and their mitochondria. Free Radical Biology and Medicine 49 674-681. (https://doi.org/10.1016/j. freeradbiomed.2010.05.025)

Mun SH, Joung DK, Kim YS, Kang OH, Kim SB, Seo YS, Kim YC, Lee DS, Shin DW, Kweon KT, et al. 2013 Synergistic antibacterial effect of curcumin against methicillin-resistant Staphylococcus aureus. Phytomedicine 20 714-718. (https://doi.org/10.1016/j. phymed.2013.02.006)

Nerlich AG \& Schleicher ED 1999 N(epsilon)-(carboxymethyl)lysine in atherosclerotic vascular lesions as a marker for local oxidative stress. Atherosclerosis 144 41-47. (https://doi.org/10.1016/S00219150(99)00038-6)

Odetti P, Rossi S, Monacelli F, Poggi A, Cirnigliaro M, Federici M \& Federici A 2005 Advanced glycation end products and bone loss during aging. Annals of the New York Academy of Sciences $\mathbf{1 0 4 3}$ 710-717. (https://doi.org/10.1196/annals.1333.082)

Paine A, Eiz-Vesper B, Blasczyk R \& Immenschuh S 2010 Signaling to heme oxygenase-1 and its anti-inflammatory therapeutic potential. Biochemical Pharmacology 80 1895-1903. (https://doi.org/10.1016/j.bcp.2010.07.014)

Park JH \& Choi TS 2012 Polycystic ovary syndrome (PCOS)-like phenotypes in the D-galactose-induced aging mouse model. Biochemical and Biophysical Research Communications 427 701-704. (https://doi.org/10.1016/j.bbrc.2012.09.099)

Paulose T, Hannon PR, Peretz J, Craig ZR \& Flaws JA 2012 Estrogen receptor alpha overexpressing mouse antral follicles are sensitive to atresia induced by methoxychlor and its metabolites. Reproductive Toxicology 33 353-360. (https://doi.org/10.1016/j. reprotox.2012.01.007)

Qin X, Cao M, Lai F, Yang F, Ge W, Zhang X, Cheng S, Sun X, Qin G, Shen W, et al. 2015 Oxidative stress induced by zearalenone in porcine granulosa cells and its rescue by curcumin in vitro. PLOS ONE 10 e0127551. (https://doi.org/10.1371/journal.pone.0127551)

Rong Y \& Distelhorst CW 2008 Bcl-2 protein family members: versatile regulators of calcium signaling in cell survival and apoptosis. Annual Review of Physiology 70 73-91. (https://doi.org/10.1146/annurev. physiol.70.021507.105852)

Rubio-Gozalbo ME, Gubbels CS, Bakker JA, Menheere PP, Wodzig WK \& Land JA 2010 Gonadal function in male and female patients with classic galactosemia. Human Reproduction Update 16 177-188. (https://doi.org/10.1093/humupd/dmp038)

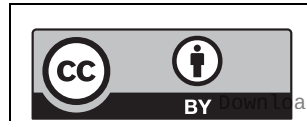

This work is licensed under a Creative Common Attribution 4.0 Unported License. 
Sanders RD, Spencer JB, Epstein MP, Pollak SV, Vardhana PA, Lustbader JW \& Fridovich-Keil JL 2009 Biomarkers of ovarian function in girls and women with classic galactosemia. Fertility and Sterility 92 344-351. (https://doi.org/10.1016/j. fertnstert.2008.04.060)

Scandalios JG 2005 Oxidative stress: molecular perception and transduction of signals triggering antioxidant gene defenses. Brazilian Journal of Medical and Biological Research 38 995-1014. (https://doi.org/10.1590/S0100-879X2005000700003)

Schinzel R, Münch G, Heidland A \& Sebekova K 2001 Advanced glycation end products in end-stage renal disease and their removal. Nephron 87 295-303. (https://doi.org/10.1159/000045934)

Seifer DB, Baker VL \& Leader B 2011 Age-specific serum anti-Müllerian hormone values for 17,120 women presenting to fertility centers within the United States. Fertility and Sterility 95 747-750. (https:// doi.org/10.1016/j.fertnstert.2010.10.011)

Semba RD, Nicklett EJ \& Ferrucci L 2010 Does accumulation of advanced glycation end products contribute to the aging phenotype? Journals of Gerontology: Series A, Biological Sciences and Medical Sciences 65 963-975. (https://doi.org/10.1093/gerona/glq074)

Seo JA, Kim B, Dhanasekaran DN, Tsang BK \& Song YS 2016 Curcumin induces apoptosis by inhibiting sarco/endoplasmic reticulum $\mathrm{Ca} 2+$ ATPase activity in ovarian cancer cells. Cancer Letters 371 30-37. (https://doi.org/10.1016/j.canlet.2015.11.021)

Shehzad A, Wahid F \& Lee YS 2010 Curcumin in cancer chemoprevention: molecular targets, pharmacokinetics, bioavailability, and clinical trials. Archiv Der Pharmazie 343 489-499. (https://doi.org/10.1002/ardp.200900319)

Sikora E, Bielak-Zmijewska A, Mosieniak G \& Piwocka K 2010 The promise of slow down ageing may come from curcumin. Current Pharmaceutical Design 16 884-892. (https://doi. org/10.2174/138161210790883507)

Simm A, Casselmann C, Schubert A, Hofmann S, Reimann A \& Silber RE 2004 Age associated changes of AGE-receptor expression: RAGE upregulation is associated with human heart dysfunction. Experimental Gerontology 39 407-413. (https://doi.org/10.1016/j. exger.2003.12.006)

Song X, Bao M, Li D \& Li YM 1999 Advanced glycation in D-galactose induced mouse aging model. Mechanisms of Ageing and Development 108 239-251. (https://doi.org/10.1016/S0047. 6374(99)00022-6)

Soto N, Iñiguez G, López P, Larenas G, Mujica V, Rey RA \& Codner E 2009 Anti-Mullerian hormone and inhibin B levels as markers of premature ovarian aging and transition to menopause in type 1 diabetes mellitus. Human Reproduction 24 2838-2844. (https://doi. org/10.1093/humrep/dep276)

Suckow BK \& Suckow MA 2006 Lifespan extension by the antioxidant curcumin in Drosophila melanogaster. International Journal of Biomedical Science 2 402-405.

Tarín JJ 1995 Aetiology of age-associated aneuploidy: a mechanism based on the 'free radical theory of ageing'. Human Reproduction 10 1563-1565. (https://doi.org/10.1093/HUMREP/10.6.1563)

Tarín JJ 1996 Potential effects of age-associated oxidative stress on mammalian oocytes/embryos. Molecular Human Reproduction 2 717-724. (https://doi.org/10.1093/molehr/2.10.717)

Terlikowska KM, Witkowska AM, Zujko ME, Dobrzycka B \& Terlikowski SJ 2014 Potential application of curcumin and its analogues in the treatment strategy of patients with primary epithelial ovarian cancer. International Journal of Molecular Sciences $\mathbf{1 5}$ 21703-21722. (https://doi.org/10.3390/ijms151221703)
Tian J, Ishibashi K, Ishibashi K, Reiser K, Grebe R, Biswal S, Gehlbach P \& Handa JT 2005 Advanced glycation endproduct-induced aging of the retinal pigment epithelium and choroid: a comprehensive transcriptional response. PNAS 102 11846-11851. (https://doi. org/10.1073/pnas.0504759102)

Tilly JL 2003 Ovarian follicle counts - not as simple as 1, 2, 3. Reproductive Biology and Endocrinology 1 11. (https://doi. org/10.1186/1477-7827-1-11)

Tiwari-Pandey R \& Ram Sairam M 2009 Modulation of ovarian structure and abdominal obesity in curcumin- and flutamide-treated aging FSH-R haploinsufficient mice. Reproductive Sciences 16 539-550. (https://doi.org/10.1177/1933719109332822)

Tolikas A, Tsakos E, Gerou S, Prapas Y \& Loufopoulos A 2011 Anti-Mullerian hormone (AMH) levels in serum and follicular fluid as predictors of ovarian response in stimulated (IVF and ICSI) cycles. Human Fertility 14 246-253. (https://doi.org/10.3109/14647273.2011.608464)

Ueki M, Ueno M, Morishita J \& Maekawa N 2013 Curcumin ameliorates cisplatin-induced nephrotoxicity by inhibiting renal inflammation in mice. Journal of Bioscience and Bioengineering 115 547-551. (https:// doi.org/10.1016/j.jbiosc.2012.11.007)

Vallianou NG, Evangelopoulos A, Schizas N \& Kazazis C 2015 Potential anticancer properties and mechanisms of action of curcumin. Anticancer Research 35 645-651.

Visser JA, de Jong FH, Laven JS \& Themmen AP 2006 Anti-Müllerian hormone: a new marker for ovarian function. Reproduction 131 1-9. (https://doi.org/10.1530/rep.1.00529)

Vlassara H, Bucala R \& Striker L 1994 Pathogenic effects of advanced glycosylation: biochemical, biologic, and clinical implications for diabetes and aging. Laboratory Investigation 70 138-151.

Voznesens'ka T, Bryzhina TM, Sukhina VS, Makohon NV \& Aleksieieva IM 2010 Effect of NF-kappaB activation inhibitor curcumin on the oogenesis and follicular cell death in immune ovarian failure in mice. Fiziolohichnyi Zhurnal 56 96-101.

Waggoner DD, Buist NR \& Donnell GN 1990 Long-term prognosis in galactosaemia: results of a survey of 350 cases. Journal of Inherited Metabolic Disease 13 802-818. (https://doi.org/10.1007/BF01800204)

Wang XN, Roy SK \& Greenwald GS 1991 In vitro DNA synthesis by isolated preantral to preovulatory follicles from the cyclic mouse. Biology of Reproduction 44 857-863. (https://doi.org/10.1095/biolreprod44.5.857)

Wang ME, Chen YC, Chen IS, Hsieh SC, Chen SS \& Chiu CH 2012 Curcumin protects against thioacetamide-induced hepatic fibrosis by attenuating the inflammatory response and inducing apoptosis of damaged hepatocytes. Journal of Nutritional Biochemistry 23 1352-1366. (https://doi.org/10.1016/j.jnutbio.2011.08.004)

Watson JL, Greenshields A, Hill R, Hilchie A, Lee PW, Giacomantonio CA \& Hoskin DW 2010 Curcumin-induced apoptosis in ovarian carcinoma cells is p53-independent and involves p38 mitogen-activated protein kinase activation and downregulation of Bcl-2 and survivin expression and Akt signaling. Molecular Carcinogenesis 49 13-24. (https://doi.org/10.1002/mc.20571)

Zhang DW, Fu M, Gao SH \& Liu JL 2013 Curcumin and diabetes: a systematic review. Evidence-based Complementary and Alternative Medicine 2013 636053. (https://doi.org/10.1155/2013/636053)

Zhang JQ, Shen M, Zhu CC, Yu FX, Liu ZQ, Ally N, Sun SC, Li K \& Liu HL 2014 3-Nitropropionic acid induces ovarian oxidative stress and impairs follicle in mouse. PLOS ONE 9 e86589. (https://doi. org/10.1371/journal.pone.0086589)

Zingg JM, Hasan ST \& Meydani M 2013 Molecular mechanisms of hypolipidemic effects of curcumin. BioFactors 39 101-121. (https:// doi.org/10.1002/biof.1072)

Received in final form 2 February 2018

Accepted 7 February 2018

Accepted Preprint published online 7 February 2018 http://jme.endocrinology-journals.org https://doi.org/10.1530/JME-17-0214
(C) 2018 The authors Published by Bioscientifica Ltd. Printed in Great Britain

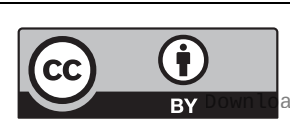

This work is licensed under a Creative Common Attribution 4.0 Unported License. ded from Bioscientifica.com at 04/26/2023 05:58:35AM 